\author{
Norman H. Anderson \\ UNIVERSITY OF CALIFORNIA, LOS ANGELES
}

\begin{abstract}
Analysis of variance provides a simple, powerful method for testing goodness-of-fit and for estimating parameters for a class of weighted sum models. Certain models for learning and other behavior changes may be reduced to weighted sum models and analyzed in the same way.
\end{abstract}

\section{Weighted sum model}

Consider a task in which $\mathrm{N}$ stimuli are presented in sequence, with each stimulus affecting the value of some numerical response measure. Only the overt response following the last stimulus will be considered explicitly. Illustrative experimental situations are discussed below.

In such tasks, it may be hypothesized that the final response is a weighted sum of the scale values of the stimuli and of the initial state of the subject prior to the first stimulus:

$$
\mathrm{X}_{\mathrm{N}}=\sum_{\mathrm{O}}^{\mathrm{N}} \mathrm{w}_{\mathrm{k}} \mathrm{s}_{\mathrm{k}}
$$

Here $\mathrm{X}_{\mathrm{N}}$ is the final response; $\mathrm{w}_{\mathrm{k}}$ and $\mathrm{s}_{\mathrm{k}}$ are the weight and value of the $k$ th stimulus for $\mathrm{k} \geq 1$; and $\mathrm{w}_{\mathrm{O}}$ and $\mathrm{s}_{\mathrm{O}}$ are the weight and value of the initial state of the subject. If the weights sum to unity, Equation 1 is a weighted average model.

Only such tasks will be considered in which, on Trial k of the sequence, any of at least two stimuli may be presented, and in which stimulus presentation is independent of any overt response. Further, it is assumed that all stimuli presented on Trial $\mathrm{k}$ have the same weight and differ only in scale value. The weights may, however, vary across trials.

\section{Goodness-of-fit test}

With these restrictions and assumptions, standard analysis of variance techniques may be employed for the model analysis. Statistical details will depend on the particular design that is used, but the basic idea may be illustrated as follows. Suppose that any of n stimuli may be presented on each trial, and that all $\mathrm{n}^{\mathrm{N}}$ possible stimulus sequences are used. These sequences then form an N-way factorial design: the factors of the design correspond to the serial positions of the sequence, and the levels of Factor k correspond to the stimuli that may be presented on Trial $\mathrm{k}$.

It can then be shown that if the weighted sum model is correct, all interactions of the design are zero. The test of goodness-of-fit is made on this basis. Significance of the observed interactions tend to infirm the model, whereas nonsignificant interactions tend to support it. Computational procedures are identical with those of the ordinary analysis of variance. It goes without saying, of course, that the same method may be employed for simultaneous as well as for serial presentation.

The above design becomes infeasibly large unless both $\mathrm{n}$ and $\mathrm{N}$ are small. At the risk of some confounding, however, fractional replications designs can markedly reduce the size of the experiment as illustrated in the following article (Anderson, 1964b).

This test of goodness-of-fit does not require estimation of the weights or scale values. If the model is correct, however, the values of these parameters would become of interest. The marginal means of the stimuli on Trial $\mathrm{k}$ are then, up to a linear transformation, equal to the corresponding values of $\mathrm{w}_{\mathrm{k}} \mathrm{s}_{\mathrm{k}}$, and hence also of $\mathrm{s}_{\mathrm{k}}$ by the assumption of equal weights. Consequently, if the same set of effective stimuli is used on every trial, the main effects of the design allow direct estimates of the relative weights. The serial position curve of these weights then portrays the influence of each serial position on the final response. Estimation of the weights is of course easier if the scale values are known.

\section{Proportional-change model}

In some tasks, the final response will be the last of a sequence of responses, overt or covert. To represent the response at an intermediate trial, a proportionalchange model may be considered:

$$
\mathrm{x}_{\mathrm{k}}=\mathrm{x}_{\mathrm{k}-1}+\mathrm{c}_{\mathrm{k}}\left(\mathrm{s}_{\mathrm{k}}-\dot{\mathrm{x}}_{\mathrm{k}-1}\right)
$$

Here $\mathrm{X}_{\mathrm{k}}$ and $\mathrm{X}_{\mathrm{k}-1}$ are the response values after and before presentation of the kth stimulus; $s_{k}$ and $c_{k}$ are the value and proportional-change parameter of the kth stimulus; and $\mathrm{X}_{\mathrm{O}}$ is the initial response value which is identified with $\mathrm{s}_{\mathrm{O}}$ above.

Equation 2 is a linear operator model for continuous response measures, and is analogous to the discrete response models of Bush \& Mosteller (1955). Its mathematical properties have been discussed in detail elsewhere (Anderson, 1964a). The above experimental restrictions will be imposed here, and it is assumed that all stimuli that can be presented on Trial $\mathrm{k}$ have the same change parameter.

If Equation 2 is written out explicitly for each $\mathrm{k}$, straightforward substitution yields $\mathrm{X}_{\mathrm{N}}$ as a function of the $c_{k}$ and $s_{k}$. This function is in fact a weighted average of the scale values, with the weights being functions of the $c_{\mathrm{k}}$. Hence, if the linear model is correct, so also is the weighted sum model. Hence also, the above test of goodness-of-fit applies to this linear model.

The weights of Equation 1 and the change parameters of Equation 2 are related thus: 


$$
\mathrm{c}_{\mathrm{k}}=\mathrm{w}_{\mathrm{k}} / \sum_{\mathrm{o}}^{\mathrm{k}} \mathrm{w}_{\mathrm{j}}
$$

If the $\mathrm{w}_{\mathrm{k}}$ and $\mathrm{s}_{\mathrm{k}}$ are known or estimated, and if the linear model applies, Equation 3 makes it possible to trace out what the trial by trial buildup of the response must have been even though only the final response is measured. This may be useful when measuring the response would affect its further development.

It should be noted, however, that although Equation 2 implies Equation 1, the converse does not hold. Equation 1 is also compatible with a finite running-sum model for trial-to-trial changes (Anderson, 1964a; Eq. 40).

\section{Diserete response models}

Although the Bush-Mosteller models apply to categorical response (Right-Left, Yes-No) rather than to numerical response measures, their equal-alpha model for experimenter-controlled events may be handled by the present method. The proof is similar to that given elsewhere (Anderson, 1964a) and rests on the fact that response probability is itself a numerical variable. This equal-alpha model is the same as has been used in applications of stimulus sampling theory to probability learning, and it can also be shown that certain of the finite state models developed in that context (Atkinson \& Estes, 1964) can be treated similarly.

The present method allows the learning parameters to change over trials which is otherwise difficult to handle. The statistical analysis, however, is slightly complicated by the desirability of pooling several replications of each stimulus sequence to get a response-proportion as the dependent variable.

\section{Discussion}

The present method is limited by the experimental restrictions that stimulus presentation be responseindependent, and that more than one stimulus be presentable on certain trials. It is also limited by the assumption that all stimuli presented on Trialk have the same weight or change parameter. Within these limitations, the method is superior to any other existing technique.

Some possible applications may now be considered. In a straight runway, the stimuli could be amount or delay of reward. The assumption of equal change parameters might be dubious, but at least the goodness-of-fit test does not require scaling the reinforcers with respect to the response dimension.
In adaptation-level theory (Helson, 1947), the AL is a weighted mean of previous stimuli. Thus the present method should be quite useful in the quantitative analysis of this theory, particularly since prior stimulus scaling is not required. An application of this kind has been made independently by Parducci \& Sandusky (in press).

In one impression-formation task, the subject receives a sequence of personality-trait adjectives, and then rates his liking of the person so described. When the subject responds only at the end of the sequence, a primacy or first-impression effect is obtained. This effect has been variously interpreted as reflecting lower weights for the later adjectives, or contextually determined changes in their meaning and value. Present evidence favors the former interpretation (Anderson, in press), but a good quantitative test has not previously been available.

Impression formation is a case of sequential information integration. Such tasks would seem especially amenable to the present formulation since the effect of a stimulus would not ordinarily be expected to depend on the subject's responses. An application to a numberaveraging task is given in the following paper (Anderson, 1964b).

\section{Referenees}

ANDERSON, N. H. Linear models for responses measured on a continuous scale. J. math. Psychol., 1964a, $1,121-142$.

ANDERSON, N. H. Test of a model for number-averaging behavior. Psychon. Sci., 1964b, 1, 191-192.

ANDERSON, N. H. Primacy effects in personality impression formation using a generalized order effect paradigm. J. abnorm. soc. Psychol., in press.

ATKINSON, R. C., \& ESTES, W. K. Stimulus sampling theory. In R. D. Luce, R. R. Bush, \& E. Galanter (Eds.), Handbook of mathematical psychology, Vol. II. New York: Wiley, 1963. Pp. 121-268.

BUSH, R. R., \& MOSTELLER, F. Stochastic models for learning. New York: Wiley, 1955.

HELSON, H. Adaptation-leyel as frame of reference for prediction of psychophysical data. Amer.J.Psychol., $1947,60,1-29$.

PARDUCCI, A., \& SANDUSKY, A. Distribution and sequence effects in judgment. J. exp. Psychol., in press.

\section{Note}

1. This work was supported by NSF Grant G-12986. 